\title{
STUDI SURVEY KELAIKAN INSTALASI LISTRIK TEGANGAN RENDAH PADA RUMAH TINGGAL SEDERHANA DENGAN DAYA 900 VA-2200 VA (Studi dilakukan pada RW 02 Kelurahan Kayu Manis Kecamatan Matraman Jakarta Timur)
}

\author{
Lea Bunga Lestari ${ }^{1}$, Purwanto Gendroyono ${ }^{2}$, Ermi Media's ${ }^{3}$ \\ 1,2,.3 Pendidikan Teknik Elektro, Fakultas Teknik, Universitas Negeri Jakarta \\ ${ }^{1}$ E-mail: lestari.bunga17@gmail.com
}

\begin{abstract}
Research of this thesis examines the feasibility of electrical installations on residential houses in $R W 02$, Kelurahan Kayu Manis Kecamatan Matraman with a power of 900 VA-2200 VA and the age of the electrical installation of more than 15 years. Refers to the standard installation of Airworthiness Requirements General Installation listri (PUIL) for housing. Collecting data by observation, documentation and measurement. Observations made on safety equipment and electrical installations to determine the quality of the electrical installation. Measurement of insulation resistance, grounding prisoners and cable cross-section to find out the quality of work of installation fixtures attached.

It can be said that in the terms of Electricity installation the feasibility, RW 02 Kelurahan Kayu Manis Kecamatan Matraman Jakarta Timur can be said to be not in accordance with the provisions of PUIL 2011. Given prisoners grounding can't be measured.

Keyword : PUIL (Persyaratan Umum Instalasi Listrik), airworthiness, electrical installation
\end{abstract}

\begin{abstract}
ABSTRAK
Riset skripsi ini meneliti tentang kelaikan instalasi listrik pada rumah tinggal sederhana di RW 02 Kelurahan Kayu Manis Kecamatan Matraman dengan daya 900 VA-2200 VA dan usia instalasi listrik lebih dari 15 tahun. Kelaikan instalasi mengacu pada standar Persayaratan Umum Instalasi Listri (PUIL) untuk rumah tinggal. Pengambilan data dengan cara observasi, dokumentasi dan pengukuran. Observasi dilakukan pada perlengkapan dan pengaman instalasi listrik untuk mengetahui kualitas instalasi listrik. Pengukuran tahanan isolasi, tahanan pembumian dan penampang kabel untuk mengetahui kualitas kerja dari perlengkapan instalasi yang terpasang.

Dalam segi kelaikan instalasi listrik di RW 02 Kelurahan Kayu Manis Kecamatan Matraman Jakarta Timur dapat dikatakan tidak sesuai dengan ketentuan PUIL 2011. Mengingat tahanan pembumian yang tidak dapat diukur.
\end{abstract}

Kata Kunci : PUIL (Persyaratan Umum Instalasi Listrik), kelaikan, instalasi listrik

\section{PENDAHULUAN}

Berdasarkan Data Kebakaran Daerah DKI Jakarta dari Dinas Penanggulangan Kebakaran dan Penyelamatan DKI Jakarta. Dapat diketahui bahwa setiap tahun kasus kebakaran yang disebabkan oleh listrik selalu yang terbanyak dari yang lainnya . Pada Tahun 2015 kasus kebakaran di daerah DKI Jakarta yang diakibatkan oleh listrik mencapai 711 kasus. Kebakaran listrik terjadi karena disebabkan pemasangan instalasi yang tidak sesuai dengan PUIL.

Kelaikan instalasi yang di survey antara lain tahanan isolasi, luas penampang kabel, permeriksaan perlengkapan instalasi listrik, pengaman yang digunakan dan tahanan pembumian.Listrik sudah menjadi kebutuhan pokok bagi kehidupan sehari-hari yang dapat dimanfaatkan untuk penerangan dan sebagai sumber peralatan rumah tangga.

\section{METODE}

\section{Lokasi Penelitian}

Tempat melakukan penelitian ini dilakukan di RW 02 Kelurahan Kayu Manis Kecamatan Matraman Jakarta Timur

\section{Metode Pengambilan Data}

Penelitian ini adalah penelitian analisis kuantitatif. Penelitian ini menggunakan metode survey deskriptif

\section{Teknik Analisis Data}

Setelah semua data diperoleh berdasarkan hasil pengukuran dan pengamatan, data akan disesuaikan dengan standar PUIL 2011. Setelah data didapat, maka akan dapat diketahui kelaikan instalasi listrik pada RW 02 Kelurahan Kayu Manis Kecamatan Matraman. 


\section{HASIL DAN PEMBAHASAN}

\section{Spesifikasi Rumah Tinggal Sederhana}

Faktor usia instalasi listrik mempengaruhi kualitas instalasi yang terpasang. Rumah yang berusia \pm 15 tahun diharuskan melakukan pemeriksaan instalasi listrik untuk menghindari terjadinya hubung singkat. Maka rumah tinggal sederhana yang menjadi sampel penelitian adalah rumah yang memasang daya listrik 900 VA-2200 VA dengan usia instalasi listrik \pm 15 tahun.

\section{Perlengkapan Instalasi Listrik}

- Penghantar

Jenis kabel yang digunakan berjenis NYM tertanam didalam dinding dan NYA terpasang didalam pipa PVC. Pemasangan pipa PVC menggunakan klem yang tertempel pada dinding dan langit-langit sebagai penghubung menuju fitting lampu. Penyambungan kabel dilakukan di dalam tdus yang terpasang rapih.

- Kotak Kontak

Pemasangan kotak kontak yang terpasang dengan ketinggian terendah dari lantai yaitu $83 \mathrm{~cm}$ dan pemasangan dengan ketinggian tertinggi dari lantai yaitu antara $144-150 \mathrm{~cm}$. Kotak kontak yang terpasang pada ketinggian terendah tidak menggunakan pelindung. Kotak kontak yang digunakan bermerk Broco, Lenka dan ada juga yang menggunakan kotak kontak yang tidak memiliki merk dagang.

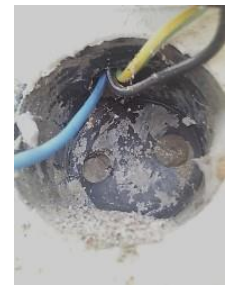

Gambar 1. Kabel pada Kotak Kontak

- Fitting dan Saklar

Fitting lampu yang digunakan berjenis fitting langit-langit yang bertumpu pada langit-langit rumah. Konduktor fasa pada lampu terhubung pada saklar sebagai penghubung dengan sumber listrik. Pemasangan saklar yang digunakan yaitu inbow dan outbow. Pada pemasangan outbow saklar dan dinding diberi pembatas dengan kayu yang berfungsi sebagai isolator. Tuas sakelar (ON/OFF) masih berfungsi dengan baik dan masih tertempel kokoh pada dinding. Penempatan sakelar pada ruangan terpasang didekat pintu atau mudah terjangkau dengan ketinggian antara 146,5$153 \mathrm{~cm}$.

- Pengaman

Rumah tinggal sederhana menggunakan pengaman jenis MCB dan sekering. Penggunaan sekering pada rumah, biasanya digunakan pada instalasi listrik lama. Karena saat ini sekering sudah jarang ditemukan dan MCB lebih mudah dicari serta digunakan. Selain itu jika terjadi gangguan dan MCB turun, maka MCB masih dapat digunakan kembali selagi tuas MCB belum mengalami penurunan kualitas. Berbeda dengan sekering jika terjadi gangguan dan sekering putus, maka sekering tidak dapat digunakan kembali. Sehingga perlu dilakukan penggantian sekering, hal ini tidak begitu ekonomis.
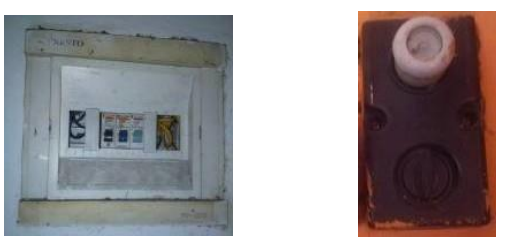

Gambar 2. PHB MCB dan Sekering

Sekering digunakan pada rumah sebagai pengaman dengan daya 900 VA. Sedangkan rumah dengan daya $1300 \mathrm{VA}$ dan $2200 \mathrm{VA}$ pengaman yang digunakan berjenis MCB. Jenis sekering dan MCB yang digunakan memiliki merk dagang Siemens, Merlin Gerin, Mentari, Schneider, Broco dan OriginalDiazed.

Besar pengaman yang digunakan pada rumah sederhana di lingkungan RW 02 Kelurahan Kayu Manis Kecamatan Mataman dapat dilihat pada tabel berikut : 
Tabel 1. Besar Pengaman

\begin{tabular}{cccccc}
\hline & \multirow{2}{*}{ No } & $\begin{array}{c}\text { Daya } \\
\text { (VA) }\end{array}$ & Jenis & \multicolumn{3}{c}{ Pengaman (A) } \\
\cline { 4 - 6 } & & Utama & $\begin{array}{c}\text { Group } \\
1\end{array}$ & $\begin{array}{c}\text { Group } \\
2\end{array}$ \\
\hline 1 & 900 & Sekering & - & 10 & - \\
2 & 900 & MCB & - & 6 & - \\
3 & 1300 & MCB & 16 & 16 & 10 \\
4 & 1300 & MCB & - & 16 & - \\
5 & 2200 & MCB & 10 & 4 & 6 \\
6 & 2200 & MCB & - & 10 & - \\
\hline
\end{tabular}

- $\quad$ Sistem Pembumian (Grounding)

Sistem grounding yang digunakan pada rumah yaitu TN-CS (Terra Netral Combined Separated) dengan menggabungkan konduktor netral dari PLN dan PE dari elektroda. Hal ini dimaksudkan jika pada gardu listrik terjadi pergesaran fasa. Maka konduktor PE yang terpasang dapat menggantikan konduktor netral yang terpasang pada instalasi listrik. Adapun sebagian rumah yang tidak menggunakan grounding pada instalasi listrik. PHB yang menggunakan sistem grounding TN-CS dua memiliki terminal netral dan grounding yang dihubungkan atau hanya memiliki satu terminal namun terdapat netral dan grounding. Sehingga terminal tersebut berfungsi sebagai penghubung. TN-CS digunakan pada KWH berjenis PraBayar.Pada pada instalasi listrik terpasang konduktor PE namun sistem pembumian menggunakan sistem TN-S (Terra Netral Separated) yaitu penghantar netral dan grounding tidak dihubungkan. Sistem ini digunakan pada KWH berjenis Pasca Bayar (Token).

\section{Hasil Pengukuran}

- Tahanan Isolasi

Pengukuran tahanan isolasi pada rumah dilakukan saat tidak bertegangan. Perlengkapan elektronik dan lampu dalam keadaan tidak terhubung dengan sumber listrik. Pengukuran dilakukan pada PHB (Papan Hubung Bagi) atau panel distribusi. Alat yang digunakan untuk mengetahui nilai tahanan pembumian yaitu megger.

Pengukuran nilai tahanan isolasi pada instalasi listrik memiliki standar kelaikan. Tahanan isolasi dikatakan laik jika memiliki nilai > 0,22 M $\Omega$. Tegangan uji yang umumnya digunakan pada yaitu $500 \mathrm{~V}$ dan resistansi $1000 \mathrm{ohm} /$ volt. Jika nilai tahanan isolasi bernilai antara $0 \mathrm{M} \Omega$ sampai $<0,22$ $\mathrm{M} \Omega$ pada instalasi, maka instalasi tersebut mempunyai kabel isolasi yang kurang baik dan sudah seharusnya diganti untuk keselamatan. Berikut hasil pengukuran tahanan isolasi di RW 02 Kelurahan Kayu Manis Kecamatan Matraman :

Tabel 2. Hasil Pengukuran Tahanan Isolasi

\begin{tabular}{ccccc}
\hline & & \multicolumn{3}{c}{ Hasil Pengukuran Tahanan } \\
Isolasi & \\
\cline { 3 - 5 } No & Daya & $\mathrm{f} / \mathrm{n}$ & $\mathrm{f} / \mathrm{g}$ & $\mathrm{n} / \mathrm{g}$ \\
\hline 1 & & 45 & - & - \\
2 & $900 \mathrm{VA}$ & 40 & 40 & 40 \\
3 & $1300 \mathrm{VA}$ & 40 & 40 & 40 \\
4 & $1300 \mathrm{VA}$ & 35 & 35 & 35 \\
5 & $2200 \mathrm{VA}$ & 50 & 50 & 50 \\
6 & $2200 \mathrm{VA}$ & 40 & 40 & 40 \\
\hline
\end{tabular}

Catatan : f/n : fasa-netral, f/g : fasa-grounding, n/g : netralgrounding

- Tahanan Pembumian

Pengukuran nilai tahanan pembumian pada instalasi listrik memiliki standar kelaikan. Tahanan pembumian dikatakan laik jika

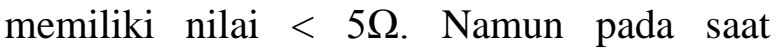
melakukan pengukuran tahanan pembumian terdapat kendala yaitu tidak adanya tanah untuk penancapan tombak bantu. Dalam mencari nilai tahanan pembumian, tempat penancapan tombak bantu berpengaruh pada nilai tahanan pembumian. Pada lingkungan RW 02 Kelurahan Kayu Manis Kecamatan Matraman merupakan wilayah padat penduduk. Keadaan lahan disekitar rumah dan jalan telah ditutupi oleh aspal dan plester. Sehingga tidak dimungkinkan melakukan pengukuran tahanan pembumian karena terkait izin dan kenyamanan warga.

- Penampang Kabel

Pengukuran luas penampang kabel dilakukan pada kotak kontak. Karena kotak kontak digunakan sebagai sumber listrik peralatan elektronik. Sehingga perlu diperhatikan besar penampang yang digunakan. Luas penampang kabel dinyatakan laik jika luas penampang kabel yang digunakan pada kotak kontak bernilai $1,5 \mathrm{~mm}^{2}$. Tabel penghantar yang digunakan kotak kontak 
pada rumah sederhana di RW 02 Kelurahan Kayu Manis Kecamatan Matraman.

\begin{tabular}{cccc}
\multicolumn{4}{c}{ Tabel 3. Penghantar Kabel Pada Kotak Kontak } \\
& Daya & $\begin{array}{c}\text { Hasil } \\
\text { Pengukuran }\end{array}$ & $\begin{array}{c}\text { Hasil } \\
\text { Perhitungan }\end{array}$ \\
\hline 1 & $900 \mathrm{VA}$ & $1,74 \mathrm{~mm}$ & $2,37 \mathrm{~mm}^{2}$ \\
2 & $900 \mathrm{VA}$ & $1,63 \mathrm{~mm}$ & $2,08 \mathrm{~mm}^{2}$ \\
3 & $1300 \mathrm{VA}$ & $1,81 \mathrm{~mm}$ & $2,57 \mathrm{~mm}^{2}$ \\
4 & $1300 \mathrm{VA}$ & $1,74 \mathrm{~mm}$ & $2,37 \mathrm{~mm}^{2}$ \\
5 & $2200 \mathrm{VA}$ & $1,81 \mathrm{~mm}$ & $2,57 \mathrm{~mm}^{2}$ \\
6 & $2200 \mathrm{VA}$ & $1,68 \mathrm{~mm}$ & $2,21 \mathrm{~mm}^{2}$ \\
\hline
\end{tabular}

\section{KESIMPULAN DAN SARAN \\ Kesimpulan}

Berdasarkan hasil penelitian, dapat

\section{disimpulkan bahwa:}

1. Berdasarkan hasil penelitian kelengkapan pemasangan dan pemilihan komponen perlengkapan instalasi listrik dan pengaman instalasi listrik yang terpasang telah sesuai dengan ketentuan PUIL 2011. Namun untuk daya 900 VA masih ditemukan ketidaksesuaian dengan standar PUIL 2011 sperti jumlah penghantar pada kotak kontak yang tidak sesuai dengan terminal kotak kontak, sakelar yang tidak terdapat merk dagang, besar pengaman yang digunakan kurang dari $10 \mathrm{~A}$ dan sistem pembumian yang digunakan tidak sesuai standar PUIL 2011.

2. Pengukuran tahanan isolasi instalasi listrik pada rumah tinggal sederhana di RW 02 telah sesuai dengan ketentuan PUIL 2011. Sedangkan pengukuran tahanan pembumian pada rumah tinggal sederhana di RW 02 tidak dapat memenuhi ketentuan PUIL 2011. Karena keadaan rumah yang terlalu berdekatan, jalan yang di aspal dan lingkungan rumah yang sudah di plester menjadi kendala yang tidak dapat dihindari. Sehingga keadaan ini tidak memadai untuk melakukan pengukuran tahanan pembumian.

3. Sistem pembumian yang terpasang masih ditemukan sistem TN-S yang tidak sesuai dengan ketentuan PUIL 2011.

4. Berdasarkan hasil penelitian kelaikan instalasi listrik pada rumah sederhana untuk daya 900 VA - 2200 VA di RW 02 Kelurahan Kayu Manis Kecamatan Matraman Jakarta Timur tidak laik berdasarkan PUIL 2011, mengingat masih ada instalasi listrik rumah yang tidak sesuai dengan standar PUIL 2011.

\section{Saran}

Berdasarkan hasil penelitian yang diperoleh, maka peneliti menyarankan:

1. Untuk PLN atau instansi yang berwenang hendaknya dapat mengevaluasi dan menindak lanjuti instalasi listrik yang tidak laik beroperasi. Agar dapat terhindar dari kebakaran yang disebabkan oleh listrik.

2. Untuk masyarakat RW 02 Kelurahan Kayu Manis Kecamatan Matraman hendaknya lebih memperhatikan instalasi yang terpasang jika terjadi kerusakan pada perlengkapan instalasi segera diganti dan menghubungi PLN atau Biro Teknik Listrik setempat, jika terjadi kerusakan yang serius. Instalasi listrik yang telah berusia 10-15 tahun, diharapkan untuk melakukan pengecekan oleh PLN atau Biro Teknik Listrik agar dapat mengetahui kondisi instalasi listrik yang terpasang. Agar dapat terhindar dari bahaya kebakaran yang disebabkan oleh instalasi listrik.

3. Untuk peneliti selanjutnya, penelitian terhadap kelaikan instalasi listrik lebih diperhatikan tanah yang terdapat dilingkungan sekitar. Karena tanah sangat mendukung dalam pengukuran tahanan pembumian.

\section{DAFTAR PUSTAKA}

Ali, Muhammad. 2013. Penelitian Kependidikan Prosedur dan Strategi. Bandung: Angkasa.

Arikunto, Suharsimi. 2013. Prosedur Penelitian Suatu Pendekatan Praktik. Jakarta: Rineka Cipta.

Hapiddin, Asep. 2009. Tata Cara Memasang Instalasi Listrik Di Rumah. Jakarta: Penebar Swadaya.

Harten, P.Van\& E. Setiawan. 1981.Instalasi Listrik Arus Kuat I. Bandung: Bina Cipta

KONSUIL. 2014. Buku Pedoman Verifikasi Hasil Pemeriksaan dan Pengujian. Jakarta: KONSUIL.

Linsley, Trevor. 2004. Instalasi Listrik Tingkat Lanjut Vol.3. Jakarta: Erlangga. 
Prastowo, Andi. 2011.Memahami MetodeMetode Penelitian. Yogyakarta: AR-RUZZ MEDIA.

Rusmadi, Dedy. 2007.Memasang dan Memperbaiki Jaringan Listrik Rumah. Bandung :Del Fajar Utama.

Singaribun, Masridan Effendi Sofian. 1995.Metode Penelitian Survey.Jakarta : LP3ES.

Standar Nasional Indonesia. 2011.PUIL 2011. Jakarta: BSN.

Sugiyono. 2010. Metode Penelitian Kuantitatif Kulaitatif dan $R \& D$. Bandung: Alfabeta.

Sumardjati, Prih. 2008 .Teknik Pemanfaatan Tenaga Listrik. Jakarta: Direktorat Pembinaan Sekolah Menengah Kejuruan.

Tim Penyusun Kamus Pusat Bahasa. 2002 .Kamus Besar Bahasa Indonesia. Jakarta: Balai Pustaka.

Waluyanti, Sri. Alat Ukur dan Teknik Pengukuran Jilid 2. Jakarta: Departemen Pendidikan Nasional.

Data Kebakaran Daerah DKI Jakarta. http://www.jakartafire.net diakses pada tanggal 8-6-2016 jam 9:51.

Tester.http://www.yf-instruments.com/
diakses pada tanggal 24-5-2016.

